\title{
Characterization of Francisella species isolated from the cooling water of an air conditioning system
}

\author{
Quan $\mathrm{Gu}^{1}$, Xunde $\mathrm{Li}^{3}$, Pinghua $\mathrm{Qu}^{2}$, Shuiping Hou ${ }^{1}$, Juntao $\mathrm{Li}^{1}$, \\ Edward R. Atwill ${ }^{3}$, Shouyi Chen ${ }^{1}$ \\ ${ }^{1}$ Guangzhou Center for Disease Control and Prevention, Guangzhou, China. \\ ${ }^{2}$ Guangdong Hospital of Traditional Chinese Medicine, University City Branch, Guangzhou, China. \\ ${ }^{3}$ Department of Population Health and Reproduction, University of California, California, USA.
}

Submitted: May 30, 2014; Approved: December 28, 2014.

\begin{abstract}
Strains of Francisella spp. were isolated from cooling water from an air conditioning system in Guangzhou, China. These strains are Gram negative, coccobacilli, non-motile, oxidase negative, catalase negative, esterase and lipid esterase positive. In addition, these bacteria grow on cysteinesupplemented media at $20^{\circ} \mathrm{C}$ to $40^{\circ} \mathrm{C}$ with an optimal growth temperature of $30^{\circ} \mathrm{C}$. Analysis of $16 \mathrm{~S}$ rRNA gene sequences revealed that these strains belong to the genus Francisella. Biochemical tests and phylogenetic and BLAST analyses of $16 \mathrm{~S}$ rRNA, rpoB and $s d h A$ genes indicated that one strain was very similar to Francisella philomiragia and that the other strains were identical or highly similar to the Francisella guangzhouensis sp. nov. strain 08HL01032 we previously described. Biochemical and molecular characteristics of these strains demonstrated that multiple Francisella species exist in air conditioning systems.
\end{abstract}

Key words: Francisella, air conditioning, water.

\section{Introduction}

Francisella is a genus of Gram-negative, coccobacilli, non-motile and aerobic bacteria (Pechous et al., 2009). Currently, five species have been recognized in the genus: $F$. tularensis, $F$. philomiragia, $F$. noatunensis, $F$. hispaniensis and F. halioticida (Brevik et al., 2011; Francis, 1922; Hollis et al., 1989; Huber et al., 2009; Ottem et al., 2009). F. tularensis was the first Francisella species to be discovered in 1912 in the USA (McCoy et al., 1912) and is the pathogen that causes tularemia in the northern hemisphere. The other species were frequently isolated in the environment or in marine fish with unknown pathogenicity to humans. One of the most common methods for identification of Francisella species is 16S rRNA gene sequencing (Barns et al., 2005; Kreizinger et al., 2013; Sjöstedt et al., 1997). In addition to the 16S rRNA gene, some housekeeping genes, such as the RNA polymerase subunit $\beta$ ( $r p o B)$ gene and the succinatede hydrogenase A $(s d h A)$ gene, have been utilized in phylogenetic analysis of Francisella (Barns et al., 2005).

It is recognized that the aerosol generated by air conditioning systems is one medium of transmission of respiratory pathogens, such as Legionella pneumophila (Stout and $\mathrm{Yu}, 1997)$. There is a knowledge gap regarding the existence of bacterial species in the cooling water of air conditioning systems. In 2008, we isolated the first strain of Francisella sp. (ID 08HL01032) (NCTC 13503) from the cooling water of an air conditioning system in Guangzhou, China (Qu et al., 2009), which was the first report of Francisella spp. isolated from air conditioning cooling water. This strain was named Francisella guangzhouensis sp. nov. (Qu et al., 2013). Between 2009 and 2011, nine additional Francisella spp. strains were isolated from the cooling water of air condition systems in the same city. Herein, we describe the biochemical characteristics and multiple gene fingerprinting of these strains, which demonstrate the presence of multiple species of Francisella and the consistent presence of Francisella guangzhouensis sp. nov. in the

Send correspondence to S. Chen. Department of Parasitic and Endemic Disease, Guangzhou Center for Disease Control and Prevention, 510440 Guangzhou, China. E-mail: shouyi_chen@163.com. 
cooling water of air conditioning systems in Guangzhou, China.

\section{Materials and Methods}

\section{Isolation of bacteria}

A total of 312 water samples were collected from cooling towers of air conditioning systems in metro stations and hotels in Guangzhou, China and were used for the detection of bacterial pathogens. Samples were collected between 2009 and 2011 as a part of the city's continuous surveillance program conducted by the Guangzhou Center for Disease Control and Prevention (GZCDC). Samples were stored at $4{ }^{\circ} \mathrm{C}$ and processed in less than 3 days after sampling. Previously described methods were used for isolation of Francisella spp. (Qu et al., 2009). Briefly, water samples $(250 \mathrm{~mL}$ each $)$ were filtered through $0.22 \mu \mathrm{m}$ polycarbonate filters. Filters with filtrate were suspended in $5.0 \mathrm{~mL}$ of sterilized water in a $50 \mathrm{~mL}$ centrifuge tube and treated with an equal volume of acid buffer $(\mathrm{pH} 2.2)$ for $5 \mathrm{~min}$ at room temperature. Then, $0.1 \mathrm{~mL}$ of the acidified suspension was placed onto Legionella-BCYE $\alpha$-agar or BCYE $\alpha-G V P C$ (BCYE $\alpha$ supplemented with 3 g glycine $\mathrm{L}^{-1}, 80,000 \mathrm{IU}$ polymyxin B sulfate $\mathrm{L}^{-1}, 1 \mathrm{mg}$ vancomycin $\mathrm{L}^{-1}$ and $80 \mathrm{mg}$ cycloheximide $\mathrm{L}^{-1}$ ) and incubated for 7 days at $30{ }^{\circ} \mathrm{C}$ under an atmosphere of $5 \% \mathrm{CO}_{2}$. Suspected colonies were inoculated onto BCYE $\alpha$ cysteine heart agar supplemented with $9 \%$ heated (chocolatized) sheep red blood cells (CHAB) and Columbia media agar, respectively, and incubated for 5 days under the same conditions as above. The BCYE $\alpha$ and CHAB media were cysteine supplemented and suitable for the growth of Francisella spp. (Petersen et al., 2009).

\section{Phenotypic characteristics}

Bacterial colonies were isolated from $\mathrm{BCYE} \alpha$ plates after 3-5 days of cultivation. Colonies of each strain were stained with Gram stain and examined with a bright field microscope (1000x). To determine the most suitable growth temperatures, a colony of each strain was inoculated into brain heart infusion broth (BHI) with L-cysteine and incubated at $20,25,30,35$ and $40^{\circ} \mathrm{C}$ for $12 \mathrm{~h}$ (Qu et al., 2009). The bacterial concentrations after incubation at each temperature were measured by a spectrophotometer at $600 \mathrm{~nm}$.

\section{Biochemical characteristics}

Colonies isolated from BCYE $\alpha$ plate after 3 days of cultivation were used for biochemical tests. Oxidase and catalase activity were tested using a BioMerieux API 20STREP kit and Vitek 2 (GN card) kit (BioMerieux). Other biochemical and enzymatic activities were tested by using API ZYM (BioMérieux) kit. Table 1 shows all of the biochemical tests performed using the three kits and the obtained results.

\section{Molecular analysis}

DNA was extracted from bacteria using a Qiagen DNA mini kit according to the manufacturer's manual. DNA concentrations were measured by a spectrophotometer at A260/A280, and those with concentrations between 1.7 and 2.1 were used as templates for PCR to amplify $16 \mathrm{~S}$ rRNA, $r p o B$, and $s d h A$ genes. For PCR of the 16S rRNA gene, approximately $1500 \mathrm{bp}$ were amplified using the primers $27 \mathrm{~F}$ and $1492 \mathrm{R}$, as described by Lane (1991). Each $50 \mu \mathrm{L}$ PCR reaction mixture included $10 \mathrm{mM}$ Tris ( $\mathrm{pH} 8.4$ ), $50 \mathrm{mM} \mathrm{KCl}, 1.5 \mathrm{mM} \mathrm{MgCl} 2,0.2 \mathrm{mM}$ deoxynucleoside triphosphates, $0.1 \mathrm{M}$ of each primer, 2.5 U Taq (TAKARA) and $1 \mu \mathrm{g}$ of genome DNA template. PCR cycles consisted of denaturation at $94{ }^{\circ} \mathrm{C}$ for $4 \mathrm{~min}$, followed by 35 cycles of $94^{\circ} \mathrm{C}$ for $30 \mathrm{~s}, 65^{\circ} \mathrm{C}$ for $40 \mathrm{~s}$, and $72{ }^{\circ} \mathrm{C}$ for $90 \mathrm{~s}$, and extension at $72^{\circ} \mathrm{C}$ for $5 \mathrm{~min}$. For PCR of the $r p o B$ gene and $s d h A$ gene, the primers used were RL1 and RL2 for the rpoB gene (Ko et al., 2002) and sdhF and sdhR for the $s d h A$ gene (Barns et al., 2005). The PCR reaction mixture and conditions for both of these genes were identical to those used for the 16S rRNA gene. PCR cycles consisted of denaturation at $94{ }^{\circ} \mathrm{C}$ for 4 min, followed by 35 cycles of $94{ }^{\circ} \mathrm{C}$ for $30 \mathrm{~s}, 50^{\circ} \mathrm{C}$ for $40 \mathrm{~s}$, and $72{ }^{\circ} \mathrm{C}$ for 90 $\mathrm{s}$, and extension at $72{ }^{\circ} \mathrm{C}$ for $5 \mathrm{~min}$. The rpoB primers amplified a 330 bp product, and the $s d h A$ primers amplified a $350 \mathrm{bp}$ product. For all PCR experiments, DNA extracted from F. philomiragia (ATCC 25015) was used as positive control and sterilized water was used as negative control. PCR products were verified by electrophoresis on $2 \%$ agarose gel stained with ethidium bromide.

The PCR products of 16S rRNA, rpoB and sdhA genes were sequenced by the Invitrogen Laboratory in Guangzhou, China, using the same primers as above. DNA sequences were analyzed using the SeqScanner 1.0 software, and the bases with a QV value less than 20 were deleted. Sequences were analyzed by multiple alignment analysis using Clustal X (Goujon et al., 2010). Sequences of currently available Francisella type species in GenBank were used to construct phylogenetic trees that were inferred using neighbor-joining analysis by the MEGA 5.0 software (Tamura et al., 2011). Bootstrap values were determined using 1,000 replicates, and Legionella pneumophila was used as out-group. For each gene, sequences were analyzed to match the maximal identical sequence by BLAST analysis using NCBI's online BLAST tool (http://blast.ncbi.nlm.nih.gov/Blast.cgi).

\section{Results and Discussion}

Nine strains of Francisella spp. bacteria (coded GZ01 to GZ-09) were isolated from 312 air conditioning cooling water locations in the city of Guangzhou. The 9 strains 
Table 1 - Comparison of biochemical characteristics of Francisella sp. strains, F. guangzhouensis sp. nov. (NCTC 13503), and F. philomiragia (ATCC25015)

\begin{tabular}{|c|c|c|c|c|}
\hline Biochemical test & Francisella spp. $^{\text {a }}$ & Francisella sp. (GZ-04) & $\begin{array}{l}\text { F. philomiragia } \\
\text { (ATCC25015) }\end{array}$ & $\begin{array}{l}\text { F. guangzhouensis sp. nov. } \\
\text { (NCTC 13503) }\end{array}$ \\
\hline Oxidase & - & - & + & - \\
\hline Catalase & W & - & W & W \\
\hline Urease & - & - & - & - \\
\hline Cysteine for growth & + & + & - & + \\
\hline PYRA & - & + & + & - \\
\hline$\alpha \mathrm{GAL}$ & - & + & + & - \\
\hline$\beta G U R$ & - & + & + & - \\
\hline$\beta G A L$ & - & + & + & - \\
\hline PAL & - & + & + & - \\
\hline LAP & - & + & + & - \\
\hline RIB & + & + & + & + \\
\hline Alkaline phosphatase & - & + & + & - \\
\hline Esterase & + & + & + & + \\
\hline Esterase lipase & + & + & + & + \\
\hline Leucine arylamidase & - & + & + & - \\
\hline Valine arylamidase & - & + & + & - \\
\hline Acid phosphatase & + & + & + & + \\
\hline Naphthol phosphohydrolase & + & + & + & + \\
\hline$\alpha$-galactosidase & - & + & + & - \\
\hline$\beta$-galactosidase & - & + & + & - \\
\hline Chitinase & - & + & + & - \\
\hline
\end{tabular}

${ }^{\mathrm{a}}$ Francisella sp. contains all strains except for GZ-04; +: positive reaction; -: negative reaction; W: weak reaction.

${ }^{\mathrm{b}}$ F. guangzhouensis sp. nov. previously isolated from cooling water of air conditioning system in Guanzhou (Qu et al., 2009; Qu et al., 2013).

were isolated from different cooling towers, except for GZ-02 and GZ-07, which were collected from the same cooling tower but from different samplings. All of these strains were Gram-negative coccobacillus (Gram stain images not shown). Bacteria of all strains grew on BCYE $\alpha$ and CHAB media, as well as on BHI with L-cysteine, but not on other media without L-cysteine, such as Columbia agar. Colonies of all strains grown on BCYE $\alpha$ medium were slightly ivory, round, convex and approximately $0.5-1.0 \mathrm{~mm}$ in diameter after 3 days of cultivation at $35^{\circ} \mathrm{C}$. Colonies on CHAB medium were light green, round and larger (1.0-1.5 mm). These strains of bacteria grow in BHI at $20^{\circ} \mathrm{C}$ to $40{ }^{\circ} \mathrm{C}$ with an optimal temperature of approximately $30{ }^{\circ} \mathrm{C}$ but did not grow at $45^{\circ} \mathrm{C}$.

All 9 strains, except for GZ-04, exhibited the same biochemical characteristics, which were almost identical to those of Francisella guangzhouensis sp. nov. (NCTC 13503), as previously reported (Qu et al., 2013). The GZ04 strain exhibited different biochemical characteristics compared to the others but was very similar to $F$. philomiragia (ATCC 25015). Table 1 shows the comparison of biochemical characteristics between these strains, $F$. guangzhouensis sp. nov., and F. philomiragia.
PCR and sequencing of $16 \mathrm{~S}$ rRNA, rpoB, and $s d h A$ genes were successful for all of the 9 strains, except for sequencing of the $s d h A$ gene for GZ-03, 06, 08, and 09. Sequences were deposited in the GenBank with accession numbers in order of the strain numbers: JN620404, KC120990, JN620406, JN620407, JN620408, JN620409, JN620410, JN620411, JN620412 for the 16S rRNA gene; KC253375， KC253382， KC253376， KC405591, KC253377, KC253378, KC253381, KC253379, and $\mathrm{KC} 253380$ for the rpoB gene; KC253383, KC253386, NA, KC253384, KC253385, NA, KC253387, NA, and NA for the $s d h A$ gene $(\mathrm{NA}=$ not available for GZ-03, 06, 08, and 09). The identities of the 16S rRNA gene sequences among these strains and the nearest sister species, $F$. philomiragia and F. guangzhouensis sp. nov. (NCTC 13503), are shown in Table 2. As shown in the table, GZ-04 was 99\% identical to $F$. philomiragia but $95 \%$ identical to $F$. guangzhouensis sp. nov. (NCTC 13503). In contrast, the other eight strains were $94-95 \%$ identical to $F$. philomiragia but $98-100 \%$ identical to F. guangzhouensis sp. nov. (NCTC 13503).

Phylogenetic trees (Figures 1, 2, and 3) were constructed with Francisella type species and Francisella-like strains from environmental samples depending on the avai- 
lability of sequences in GenBank. As shown in the figures, all of the Francisella sp. strains, with the exception of GZ-04, formed a well-defined branch, including $F$ guangzhouensis sp. nov. The GZ-04 strain formed a separated branch with $F$. philomiragia. Specifically, the 9 strains formed 3 clusters: cluster 1 (GZ-01, 02, 05), cluster

Table 2 - Comparison of identity (percentage) of 16S rRNA gene of Francisella sp. strains, F. guangzhouensis sp. nov. (NCTC 13503), and F. philomiragia (ATCC25015).

\begin{tabular}{|c|c|c|c|c|c|c|c|c|c|}
\hline ID of strains & GZ -01 & GZ -02 & GZ -03 & GZ -04 & GZ -05 & GZ -06 & GZ -07 & GZ -08 & GZ -09 \\
\hline GZ -01 & $100 \%$ & & & & & & & & \\
\hline GZ -02 & $99 \%$ & $100 \%$ & & & & & & & \\
\hline GZ -03 & $98 \%$ & $98 \%$ & $100 \%$ & & & & & & \\
\hline GZ -04 & $95 \%$ & $95 \%$ & $95 \%$ & $100 \%$ & & & & & \\
\hline GZ -05 & $99 \%$ & $100 \%$ & $98 \%$ & $95 \%$ & $100 \%$ & & & & \\
\hline GZ -06 & $98 \%$ & $98 \%$ & $100 \%$ & $95 \%$ & $98 \%$ & $100 \%$ & & & \\
\hline GZ -07 & $98 \%$ & $98 \%$ & $100 \%$ & $95 \%$ & $98 \%$ & $100 \%$ & $100 \%$ & & \\
\hline GZ -08 & $98 \%$ & $98 \%$ & $99 \%$ & $94 \%$ & $98 \%$ & $99 \%$ & $99 \%$ & $100 \%$ & \\
\hline GZ -09 & $98 \%$ & $98 \%$ & $99 \%$ & $95 \%$ & $98 \%$ & $99 \%$ & $99 \%$ & $99 \%$ & $100 \%$ \\
\hline F. philomiragia & $95 \%$ & $95 \%$ & $95 \%$ & $99 \%$ & $95 \%$ & $94 \%$ & $94 \%$ & $94 \%$ & $95 \%$ \\
\hline F. guangzhouensis sp. nov. ${ }^{\text {a }}$ & $99 \%$ & $100 \%$ & $98 \%$ & $95 \%$ & $100 \%$ & $98 \%$ & $98 \%$ & $98 \%$ & $98 \%$ \\
\hline
\end{tabular}

${ }^{\mathrm{a}}$ F. guangzhouensis sp. nov. previously isolated from the cooling water of an air conditioning system in Guangzhou (Qu et al., 2009; Qu et al., 2013).

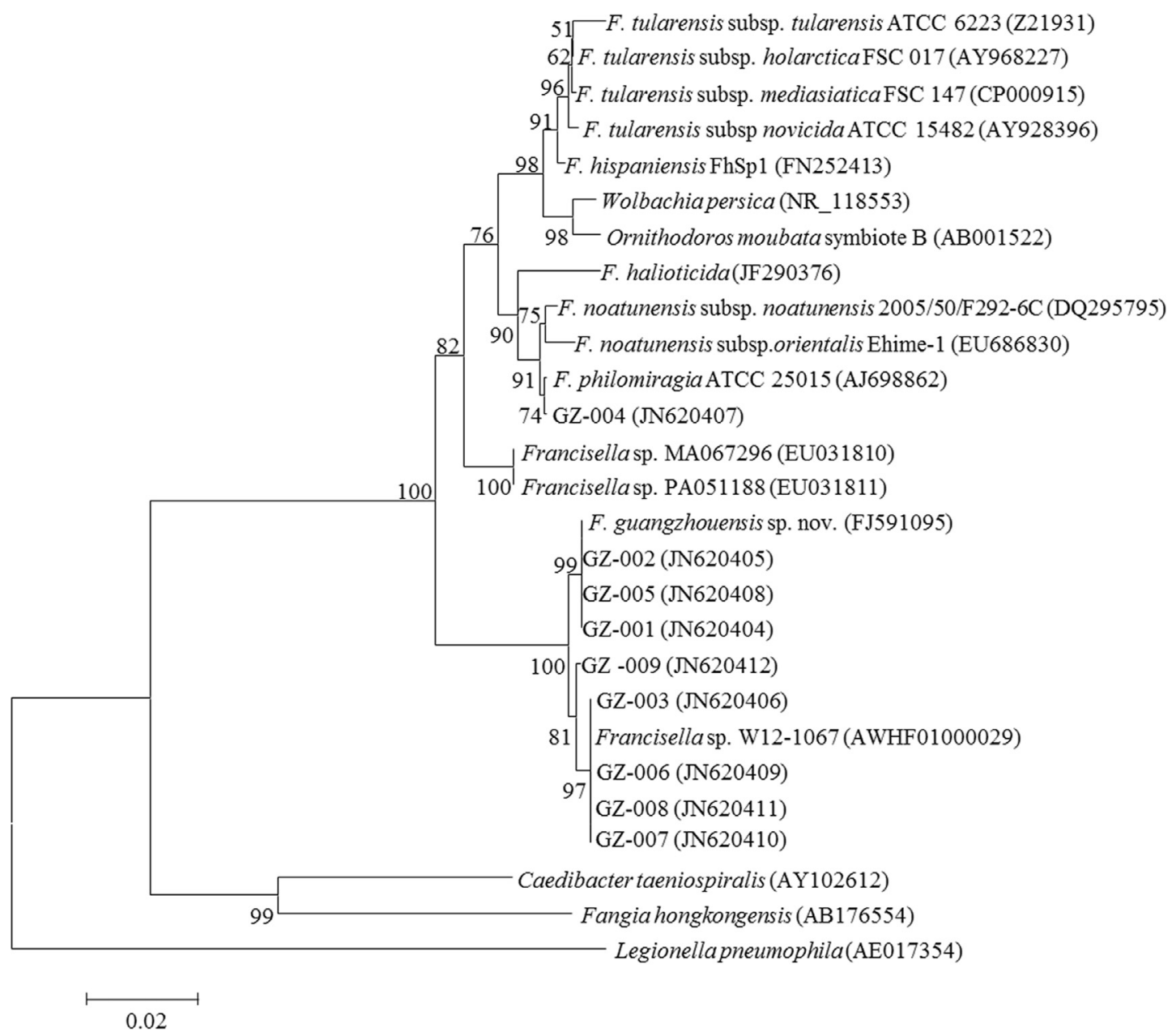

Figure 1 - Phylogenetic analysis of the 16S rRNA gene. The significance of branches is indicated by bootstrap values calculated for 1000 replications. $L$. pneumophila was used as an out-group. 


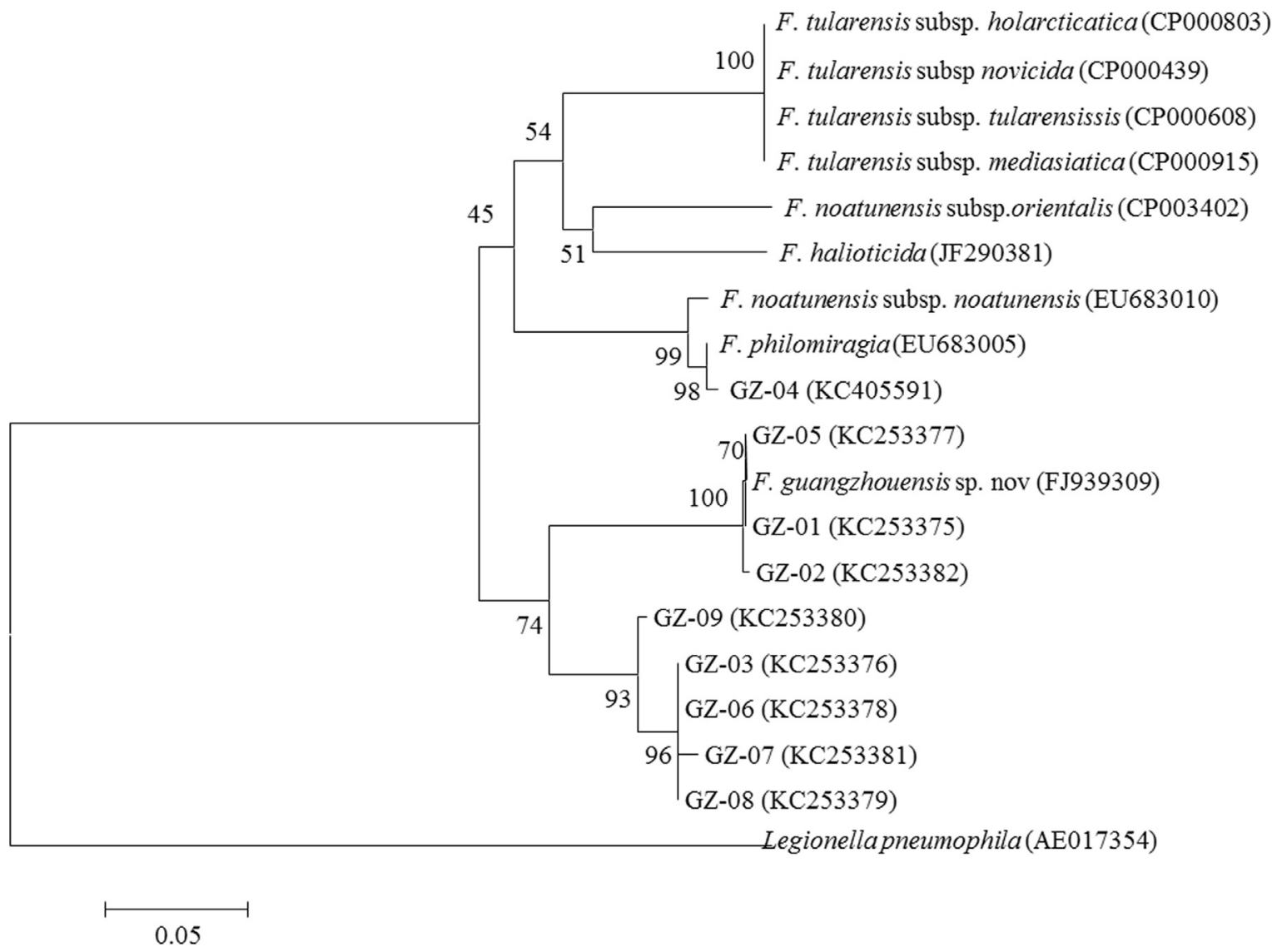

Figure 2 - Phylogenetic analysis of the rроB gene. The significance of branches is indicated by bootstrap values calculated for 1000 replications. $L$. pneumophila was used as an out-group.

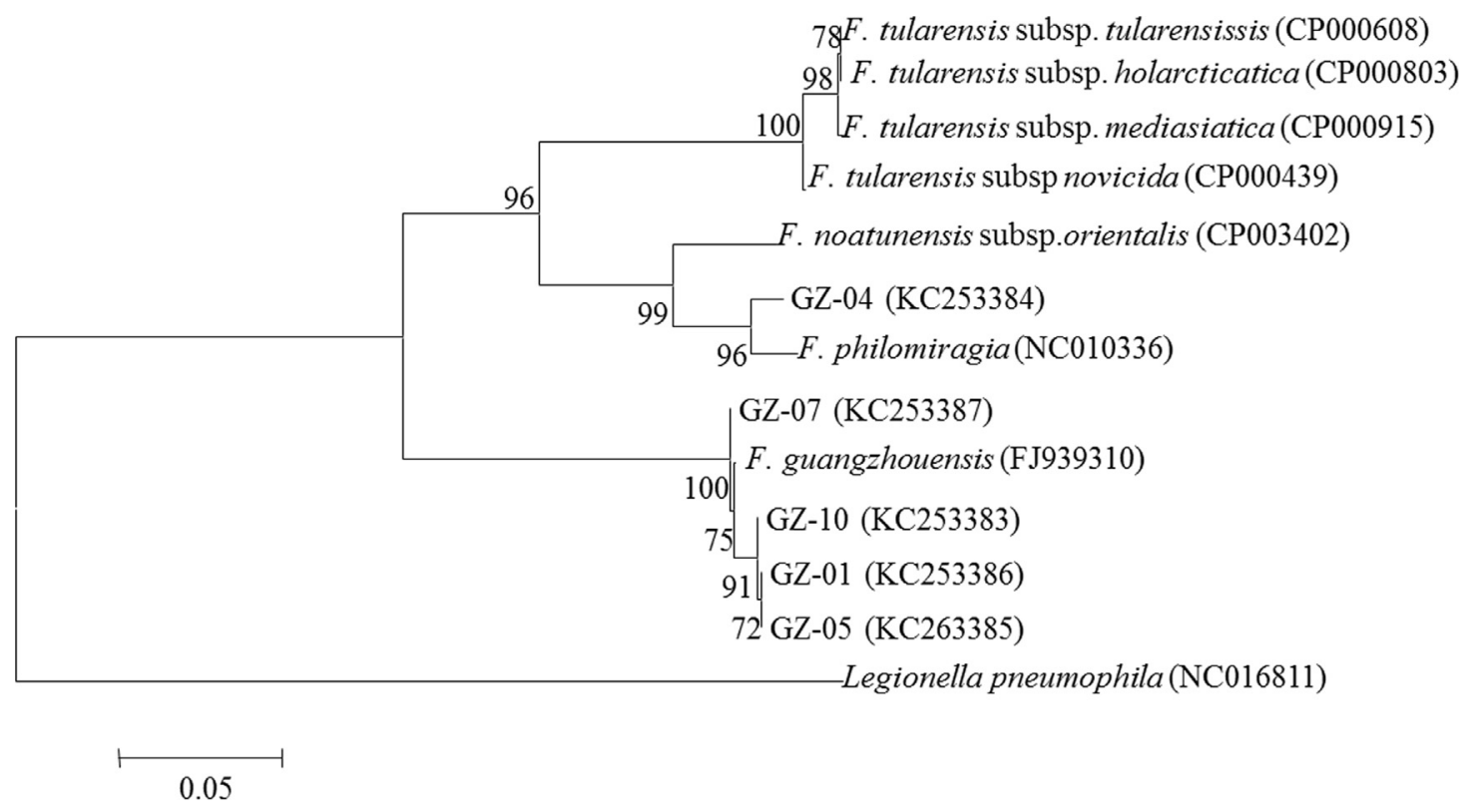

Figure 3 - Phylogenetic analysis of the $s d h A$ gene. Sequences of strains GZ-03, GZ-06, GZ-08, and GZ-09 were not available due to the failure of PCR or sequencing of these strains. The significance of branches is indicated by bootstrap values calculated for 1000 replications. L. pneumophila was used as an out-group. 
2 (GZ-03, 06, 07, 08, 09), and cluster 3 (GZ-04) (sequences of the $s d h A$ gene were not available for GZ-03, 06, 08, and 09). For all of the 3 genes, cluster 3 was consistently in the same clade with $F$. philomiragia (Figures 1, 2, and 3). For 16S rRNA and rpoB genes, cluster 1 was identical to $F$. guangzhouensis sp. nov. and showed high identity with cluster 2 (Figures 1 and 2). For the $s d h A$ gene, cluster 2 showed slightly higher identity to $F$. guangzhouensis sp. nov. than cluster 1 (Figure 3). Interestingly, Francisella sp. W12-1067 (AWHF01000029) was grouped in the same clade as cluster 2 . This strain was isolated from a cooling tower from a hospital in Germany and was not $F$. tularensis (Rydzewski et al., 2014).

BLAST analysis of the sequences of $16 \mathrm{~S}$ rRNA and sdhA genes consistently demonstrated that all strains of clusters 1 and 2 shared $99-100 \%$ identity with each other and between $F$. guangzhouensis sp. nov. but were 95\% identical to $F$. philomiragia and $F$. tularensis (16S rRNA gene) and $80-85 \%$ to other Francisella spp. isolates (sdhA). Cluster 3 (GZ-04) was $99 \%$ identical to $23 F$. philomiragia, $5 F$. piscicida, and $5 F$. noatunensis isolates with the $16 \mathrm{~S}$ rRNA gene and $98 \%$ identical to $14 F$. philomiragia isolates with the $s d h A$ gene. For the rpoB gene, strains of cluster 1 were $100 \%$ identical to $F$. guangzhouensis sp. nov. (NCTC 13503) and $87 \%$ identical to a strain of $F$. noatunensis; strains of cluster 2 were $91 \%$ identical to $F$. guangzhouensis sp. nov. (NCTC 13503) and $77-88 \%$ to Legionella anisa and Mycoplasma fermentans or $F$. philomiragia. Cluster 3 was $99 \%$ identical to $F$. guangzhouensis sp. nov. (NCTC 13503) and 87\% to 3 isolates of $F$. noatunensis (as of BLAST analysis completed on May 24, 2014).

As described above, the biochemical characteristics, identity of the 16S rRNA gene, and phylogenetic and BLAST analyses with multiple genes were consistent in differentiating the 9 strains of Francisella. One of the 9 strains (GZ-04) was very similar to $F$. philomiragia but presented some different molecular and biochemical characteristics indicating that GZ-04 may be a new strain of $F$. philomiragia or perhaps a new species. F. philomiragia is a rare and opportunistic species that can cause invasive infection in patients with compromised neutrophil function (Mailman and Schmidt, 2005). The presence of Francisella species similar to $F$. philomiragia indicate the potential risk of human infection in the case of exposure to contaminated air conditioning cooling water. Interestingly, regarding the 16S rRNA and $s d h A$ genes, 8 of the 9 strains (clusters 1 and 2) were identical or very similar $(99-100 \%)$ to $F$. guangzhouensis sp. nov. (NCTC 13503) detected in 2008. For the rpoB gene, strains of cluster 1 were also $100 \%$ identical to $F$. guangzhouensis sp. nov. (NCTC 13503), but strains of cluster 2 were only $91 \%$ identical to $F$. guangzhouensis sp. nov. (NCTC 13503). These findings demonstrate the consistent existence of $F$. guangzhouensis sp. nov., including new isolates (isolates in clusters 1 and 2) and potentially more new species in the cooling water of air conditioning systems in Guangzhou.

Virulence genes and pathogenicity islands have been frequently reported in Francisella strains (Faron et al., 2013; Hare and Hueffer, 2014; Law et al., 2014; Long et al., 2013). Although we did not analyze Francisella virulence genes and pathogenicity islands due funding limitations and the scope of this work, our findings warrant future studies to understand the pathogenicity of Francisella spp. strains from air conditioning systems. Legionella was not detected in the samples used in this work (collected between 2009 and 2011) but was detected in routine surveillance samples collected after 2011. Worldwide, Legionella was detected in cooling water in Germany (Freudenmann et al., 2011), Greece (Mouchtouri et al., 2010), Poland (Matuszewska and Krogulska, 2008), Spain (Pérez et al., 2011), and the USA (Stout and Yu, 1997). The detection of pathogenic bacteria from the cooling water of air conditioning systems suggests a potential risk to public health and the need for continuous surveillance. In the present work, using biochemical characterizations and multiple gene fingerprinting approaches, we confirmed the consistent presence of $F$. guangzhouensis sp. nov. and potentially novel species of Francisella sp. that are very similar to $F$. philomiragia in the cooling water of air conditioning systems in Guangzhou. Isolation, identification and characterization of these bacteria in cooling water filled the gap of knowledge concerning Francisella spp. in air conditioning systems. Findings from this study demonstrate a potential public health risk and warrant future work to study the source and routes of contamination, the pathogenicity of Francisella spp. and possible interventions to prevent outbreaks associated with contaminated air conditioning cooling water.

\section{Acknowledgments}

This study was supported by Guangzhou Science and Technology Program (No. 2010J-E391) and project for Key Medicine Discipline Construction of Guangzhou Municipality (2013-2015-07).

\section{References}

Barns SM, Grow CC, Okinaka RT et al. (2005) Detection of diverse new Francisella-Like bacteria in environmental samples. Appl Environ Microbiol 71:5494-5500.

Brevik OJ, Ottem KF, Kamaishi T et al. (2011) Francisella halioticida sp. nov., a pathogen of farmed giant abalone (Haliotis gigantea) in Japan. J Appl Microbiol 111:10441056.

Faron M, Fletcher JR, Rasmussen JA et al. (2013) The Francisella tularensis migR, trmE, and cphA genes contribute to $F$. tularensis pathogenicity island gene regulation and intracellular growth by modulation of the stress alarmone ppGpp. Infect Immun 81:2800-2811. 
Francis E (1922) TULAREMIA Francis 1921: A new gisease of man. JAMA 78:1015-1018.

Freudenmann M, Kurz S, von Baum H et al. (2011) Interdisciplinary management of a large Legionella outbreak in Germany. Bundesgesundheitsblatt Gesundheitsforschung Gesundheitsschutz 54:1161-1169.

Goris J, Konstantinidis KT, Klappenbach JA et al. (2007) DNADNA hybridization values and their relationship to wholegenome sequence similarities. Int J Syst Evol Microbiol 57:81-91.

Goujon M, McWilliam H, Li W et al. (2010) A new bioinformatics analysis tools framework at EMBL-EBI. Nucleic Acids Res 38:W695-699.

Hollis DG, Weaver RE, Steigerwalt AG et al. (1989) Francisella philomiragia comb. nov. (formerly Yersinia philomiragia) and Francisella tularensis biogroup novicida (formerly Francisella novicida) associated with human disease. J Clin Microbiol 27:1601-1608.

Hare RF, Hueffer K (2014) Francisella novicida pathogenicity island encoded proteins were secreted during infection of macrophage-like cells. PLoS One 9:e105773.

Huber B, Escudero R, Busse HJ et al. (2009) Description of Francisella hispaniensis sp. nov., isolated from human blood, reclassification of Francisella novicida (Larson et al., 1955) Olsufiev et al., 1959 as Francisella tularensis subsp. novicida comb. nov. and emended description of the genus Francisella. Int J Syst Evol Microbiol 60:1887-1896.

Janda JM, Abbott SL (2007) 16S rRNA gene sequencing for bacterial identification in the diagnostic laboratory: pluses, perils, and pitfalls. J Clin Microbiol 45:2761-2764.

Ko KS, Lee HK, Park MY et al. (2002) Application of RNA polymerase beta-subunit gene (rpoB) sequences for the molecular differentiation of Legionella species. J Clin Microbiol 40:2653-2658

Kreizinger Z, Hornok S, Dán A et al. (2013) Prevalence of Francisella tularensis and Francisella-like endosymbionts in the tick population of Hungary and the genetic variability of Francisella-like agents. Vector Borne Zoonotic Dis 13:160-163.

Law HT, Sriram A, Fevang C et al. (2014) IglC and PdpA are important for promoting Francisella invasion and intracellular growth in epithelial cells. PLoS One 9:e104881.

Lane DJ (1991) 16S/23S rRNA sequencing. In: Stackebrandt E, Goodfellow M (eds) Nucleic Acid Techniques in Bacterial Systematics. John Wiley \& Sons, Chichester, p. 115-175.

Long ME, Lindemann SR, Rasmussen JA et al. (2013) Disruption of Francisella tularensis Schu S4 iglI, iglJ, and pdpC genes results in attenuation for growth in human macrophages and in vivo virulence in mice and reveals a unique phenotype for pdpC. Infect Immun 81:850-861.

Mailman TL, Schmidt MH (2005) Francisella philomiragia adenitis and pulmonary nodules in a child with chronic granulomatous disease. Can J Infect Dis Med Microbiol $16: 245-248$.
Matuszewska R, Krogulska B (2008) Occurrence of bacteria from the Legionella genus in cooling water systems. Rocz Panstw Zakl Hig 59:445-454.

McCoy GW, Chapin CW (1912) Further observations on a plague-like disease of rodents with a preliminary note on the causative agent Bacterium tularense, J Infect Dis 10:61-72.

Mouchtouri VA, Goutziana G, Kremastinou J et al. (2010) Legionella species colonization in cooling towers: risk factors and assessment of control measures. Am J Infect Control 38:50-55.

Ottem KF, Nylund A, Karlsbakk E, Friis-Moller A, Kamaishi T (2009) Elevation of Francisella philomiragia subsp. noatunensis Mikalsen et al. (2007) to Francisella noatunensis comb. nov. [syn. Francisella piscicida Ottem et al. (2008) syn. nov.] and characterization of Francisella noatunensis subsp. orientalis subsp. nov., two important fish pathogens. J Appl Microbiol 106:1231-1243.

Pechous RD, McCarthy TR, Zahrt TC (2009) Working toward the future: insights into Francisella tularensis pathogenesis and vaccine development. Microbiol Mol Biol Rev 73:684-711.

Petersen JM, Carlson J, Yockey B et al. (2009) Direct isolation of Francisella spp. from environmental samples. Lett Appl Microbiol 48:663-667.

Pérez LM, Codony F, Ríos K et al. (2011) Prevalence study of Simkania negevensis in cooling towers in Spain. J Water Health 9:312-316.

Qu PH, Chen SY, Scholz HC et al. (2013) Francisella guangzhouensis sp. nov., isolated from air-conditioning systems. Int J Syst Evol Microbiol 63:3628-3635.

Qu P, Deng X, Zhang J et al. (2009) Identification and characterization of the Francisella sp. strain 08HL01032 isolated in air condition systems. Acta Microbiol Sin 49:1003-1010.

Rydzewski K, Schulz T, Brzuszkiewicz E et al. (2014) Genome sequence and phenotypic analysis of a first German Francisella sp. isolate (W12-1067) not belonging to the species Francisella tularensis. BMC Microbiol 14:169.

Sjöstedt A, Eriksson U, Berglund L et al. (1997) Detection of Francisella tularensis in ulcers of patients with tularemia by PCR. J Clin Microbiol 35:1045-1048.

Stout JE, Yu VL (1997) Legionellosis. N Engl J Med 337:682687.

Tamura K, Peterson D, Peterson N et al. (2011) MEGA5: molecular evolutionary genetics analysis using maximum likelihood, evolutionary distance, and maximum parsimony methods. Mol Biol Evol 28:2731-2739.

Ziemke F, Hofle MG, Lalucat J et al. (1998) Reclassification of Shewanella putrefaciens Owen's genomic group II as Shewanella baltica sp. nov. Int J Syst Bacteriol 48:179-186.

Associate Editor: Rodrigo da Silva Galhardo

All the content of the journal, except where otherwise noted, is licensed under a Creative Commons License CC BY-NC. 